\title{
No effect of verapamil on calcium stimulated calcitonin release
}

\author{
J.A. Amado, C. Gómez, C. Pesquera, M.A. Antón, J. Freijanes and J. González \\ Macías.
}

Endocrine Unit, Department of Medicine, Valdecilla Hospital, School of Medicine, 39008 Santander, Spain

\begin{abstract}
Summary: We investigated the effect of infusing $5 \mathrm{mg} / \mathrm{h}$ of verapamil on calcitonin release in normal males. After 60 minutes of infusion, ionized calcium and calcitonin levels were unchanged. At 60 minutes we infused $3 \mathrm{mg} / \mathrm{kg}$ of body weight of elemental calcium over 10 minutes and we found that calcitonin release was no different from when the subjects were receiving verapamil. These results suggest that, despite blocking calcium channels, acute hypercalcaemia produces normal calcitonin release.
\end{abstract}

\section{Introduction}

Calcium channel blockers are widely used in the treatment of different cardiovascular disorders. In addition to their effect as inhibitors of calcium influx into the cells they can inhibit the availability of $\mathrm{Ca}^{++}$ for excitation contraction coupling at an intracellular site. ${ }^{1}$ Recent studies have suggested that some calcium antagonists may diminish insulin, glucagon, follicle stimulating hormone (FSH), luteinizing hormone (LH), growth hormone (GH), thyroid stimulating hormone (TSH) and ACTH release after different stimuli both in vitro and in vivo. ${ }^{2,3,4}$ Since calcium is the major regulator of the function of C-cells of the thyroid we evaluated the effect of verapamil, a wellknown calcium antagonist, on basal and calciumstimulated calcitonin release.

\section{Material and methods}

Fifteen normal males, aged 20-42 years, were studied after they gave their informed consent. None of them was obese, had evidence of diseases known to affect calcium metabolism or was taking any kind of drug. We excluded four of them because basal calcitonin levels were lower than the sensitivity of our assay. We excluded two further subjects because no calcitonin response was found after calcium infusion. So results are given of nine subjects in whom basal calcitonin levels were detected in our assay and who showed a measurable calcitonin response to calcium infusion.

All subjects were studied on two different days at $08.30 \mathrm{~h}$ after an overnight fast $(0$ time). Protocol A consisted of infusing normal saline at a rate of $100 \mathrm{ml} / \mathrm{h}$ over 2 hours. At 60 minutes $3 \mathrm{mg} / \mathrm{kg}$ of body weight

Correspondence: J.A. Amado, M.D.

Accepted: 30 July 1986 of elemental calcium as calcium gluconogalactogluconate (Calcium Sandoz [TM]) was infused over 10 minutes. Blood samples were obtained from a different vein for ionized calcium and calcitonin at 0 , $60,70,80,90,105$ and 120 minutes. Protocol B consisted of infusing $5 \mathrm{mg} / \mathrm{h}$ verapamil i.v. (Manidon Knoll [TM]) diluted in normal saline $100 \mathrm{ml} / \mathrm{h}$ over 2 hours. At 60 minutes calcium was infused as in protocol $\mathrm{A}$ and blood samples were obtained at the same times as in protocol A. Cardiac rate and blood pressure were evaluated at 0,60 and 120 minutes. To begin with either protocol A or B was chosen at random and the second protocol was performed a week after the first.

Serum was obtained anaerobically and stored on ice until it was used for determination of ionized calcium with a Space Stat 20 ionized calcium analyzer (Orion Biomedical, Cambridge MA). ${ }^{5}$ Calcitonin was measured in duplicate by a direct RIA using a kit furnished by Immunonuclear Corp., Stillwater MN. Interassay coefficient of variation for ionized calcium was $1.3 \%$ at a concentration of $1.1 \mathrm{mmol} / 1$. To avoid interassay variations in calcitonin all samples from one subject were measured in a single assay. Intraassay coefficient of variation was $5 \%$ at $100 \mathrm{pg} / \mathrm{ml}$. Sensitivity was $25 \mathrm{pg} / \mathrm{ml}$.

Results are given as mean \pm s.e.m.. Statistical analysis was done using paired Student's $t$ test. Results were considered significant if $P<0.05$.

\section{Results}

Ionized calcium and calcitonin levels are shown in Table I. We found no significant effect of verapamil on calcium or calcitonin after $\mathbf{6 0}$ minutes infusion. Likewise calcium-stimulated calcitonin release was not significantly different during verapamil infusion. 
Discussion

Calcium antagonists could alter calcitonin release by inhibiting the entry of calcium ions into the C-cells of the thyroid, but in this study we found no significant $\underset{\vec{\rho}}{\vec{\rho}}$ effects of therapeutic doses of verapamil on calcitonin $\overrightarrow{0}$ secretion. At these doses of verapamil the release of $\frac{c}{0}$ other hormones is diminished. ${ }^{6}$ These results are in $\overline{\bar{\omega}}$. accordance with that presented by Deedwania et al. ${ }^{7}$ who found no effect of oral nifedipine at therapeutic doses on the long-term calcium, calcitonin and parathyroid hormone levels in a group of patients with $\vec{\circ}$ angina pectoris.

We can only speculate on the possible mechanisms $\vec{\omega}$ for the failure of verapamil to inhibit calcitonin release, which include (a) the possible selectivity of action of verapamil, i.e. calcium channels in various cells are not affected in the same way, and (b) that the effects of verapamil are overcome by increased concentrations of extracellular calcium, in the case of calcium-stimulated calcitonin release.

\section{Acknowledgements}

We thank Ms B. Paule, Ms C. Renteria and Ms I. Villa for their technical assistance.

\section{References}

1. Zsoter, T.T. \& Church, J.G. Calcium antagonist. Pharmacodynamic effects and mechanism of action. Drugs 1983, 25: 93-112.

2. Davis, G., Somers, G., Van Obberghen, E. \& Malaisse, W. Calcium antagonists and islet function. I. Inhibition of insulin release by verapamil. Diabetes $1975,24: 547-551$.

3. Eto, S, McMillen-Wood, J., Hutchins, M. \& Fleischer, N. Pituitary ${ }^{45} \mathrm{Ca}$ uptake and release of ACTH, GH and TSH: effect of verapamil. Am J Physiol 1974, 226: 1315-1320.

4. Barbarino, A. \& De Marinis, L. Calcium antagonists and hormone release. II. Effects of verapamil on basal, 3 gonadotropin-releasing hormone and thyrotropin-releasing hormone-induced pituitary hormone-release in normal subjects. J Clin Endocrinol Metab 1980, 51: 749-753.

5. Larsson, L. \& Ohman, S. (1985). Effect of siliconeseparator tube and storage time on ionized calcium in serum. Clin Chem 1985, 31: 169-170.

6. De Marinis, L. \& Barbarino, A. Calcium antagonists and hormone release. I. Effects of verapamil on insulin release in normal subjects. Metabolism 1980, 29: 599-604.

7. Deedwania, P.C., Kukreja, S.C., Mann, L.T. \& Williams, ๑ G.A. Effects of nifedipine on serum calcium, calcitonin, $N$ and parathyroid hormone in man. In Cohn, D.V., Potts, N J.T., Jr. \& Fujita, T. (eds) Endocrine Control of Bone and Calcium Metabolism, Vol 8b. Elsevier Science Publishers BV, Amsterdam, 1984, pp.282-285. 